\title{
Management and Leadership in Colleges and Universities
}

\author{
Libby V. Morris ${ }^{1}$
}

Published online: 25 November 2015

(C) Springer Science+Business Media New York 2015

Recently, I met with faculty members who are participating in a campus-based leadership development program. The participants were interested in preparation for leadership, the challenges in administration, and general advice. First, I unequivocally state that leadership of complex organizations is difficult, and my perspective is only a small window into the hundreds of books and thousands of articles on this topic.

A classic among the books is Reframing organizations: Artistry, choice and leadership. Authors Bolman and Deal (2013) provide four frames or lenses through which decisions and activities can be considered or analyzed. In a nutshell, the structural frame is characterized by roles, formal relationships, teams, rules, policies, and procedures. The human resources frame is about people and their needs, skills, relationships, and attitudes. The political frame raises questions of power and conflict, competition for resources, and coalitions. The symbolic frame deals with purpose and meaning, institutional culture, rituals and symbols.

An understanding of these lenses may indeed assist an administrator in the analysis of issues and in contemplating strategies for action. For example, colleges often adopt or imitate programs and procedures from another institution only to encounter vastly different results because transferability can be dramatically affected by differences in purpose and culture. Similarly, a propensity to view leadership as improved structure will bring about an intensity in revising policies, implementing new rules and regulations, and a focus on reorganization. The structural frame often seems to be paired with authoritative approaches to leadership and the exercise of power. In higher education, shared governance is an expectation of the faculty, and unilateral decision-making will erode support for goals and initiatives. Based on professional expertise, faculty members claim some right to make academic decisions about research and instruction, about who will be their peers, and the quality of their work and others.

The new managerialism in higher education is really not so new. For the past decade, colleges have expanded administrative structures and added administrators throughout the multi-tiered structure in order to meet the escalating demands arising from federal and state governments and agencies, to satisfy the criteria and standards for accountability by accrediting bodies, and to meet the demands of students for a wide-range of academic support

Libby V. Morris

lvmorris@uga.edu 
and extracurricular services. Needless to say, good management is essential: budgets must be balanced; facilities must be erected and maintained; essential services in food, transportation and housing must exhibit both functionality and quality. Yet, many governing bodies and some presidents fail to recognize that colleges and the corporate sector are quite different and that sound management may only be partially effective in a professional-based culture. While management is essential, it is not sufficient.

Aspiring academic leaders need to understand the organizational complexity of colleges and universities and the wisdom in shared decision-making. Effective leaders avoid the exercise of unilateral power; they have a clear understanding of who has the authority and/ or responsibility for decision-making, and they respect the roles of various groups and constituents (faculty, staff, students, alumni, legislators, etc.) in the process. Leaders know whom to consult — formally and informally — and when to bring about change. If an administrator is exclusively focused on revising rules and policies to raise standards, the important role of cultural fit (symbolic lens) to bring about change may be overlooked. Without consultation with the legitimate stakeholders in goal setting and decision-making, improved practice may not follow policy. Without visible respect and empathy for multiple constituents who carry out the work, every day, on multiple levels, only mediocrity will prevail (human relations lens).

Across higher education institutions, the number of formal positions of academic leader are limited; and those who prioritize management over leadership will fail to tap into the vision and commitment of the constituents to bring about excellence. Respect and collaboration are aligned with the "carrot" of rewards, while developing more stringent policies and tightening procedures may aligns with the "stick" of enforcement. Creativity, entrepreneurship, innovation, educated citizens - all of the things we need from our great colleges and universities align with a deft handling of the need for policies, the reality of layered organizations, the inevitability of politics, and a recognition of the overwhelming importance of the rank and file. Yes, knowledge and codification of standards are important; being accountable for demonstrating and benchmarking progress is necessary; but, in the end, counting and measuring and reporting and assessing are insufficient to engender commitment, enthusiasm, trust, and a willingness to go the extra mile. People must be valued and respected (human resources); otherwise, the most finely tuned policies may be for naught. What is most worrisome now is the preoccupation with the management function by trustees and some senior administrators, leading to not-so-good outcomes. So, what did I tell the enthusiastic faculty members aspiring to be administrators?

First, your basic personality will interact with all of the frames, but you must first know yourself-your strengths, weaknesses, aspirations, and predominant lens. Some leaders may be a bit more "born" to the job; but the skills required of a leader can be identified, learned, and practiced. Knowledge is important, and limited information is dangerous. Learn the overarching framework for the management role, but remember there are professional managers who work in various silos of the organizational structure (e.g., fiscal affairs) who will always be the expert on specific questions. Leaders should know how to frame the discussion and bring judgement to decisions.

Relationships are important. Who has the needed information? Who should be trusted to supply accurate information? Who is collaborative? The human relations dimension of work should not be dismissed. Learn how to create teams, inspire and reward collaboration, and use available information. Build trust; it allows for the two-way flow of communication and delegation. 
Power should be used judiciously; unbridled authority creates distrust, inhibits communication, and enables disruptive behind-the-scenes maneuvers. Do not be tone-deaf to the constituent's need for a sense of transparency, fairness, and equity. Clear, consistent communication is a core skill to refine. Seek to understand the symbols, metaphors, and rituals of the institution; and honor the heritage and traditions even as you struggle to understand the culture. Finally, the leader ultimately must have a vision to lead for excellence, not manage for mediocrity. James Downey (2001), former president of the University of Waterloo, confirmed the importance of the human relations and symbolic lenses in a quote about university leadership: "Visions in universities are not manufactured: they are harvested. The president's role is to take the lead in cultivating an institutional climate where openness, mutual respect, and the release of creative energies are valued as acts of leadership in themselves" (p. 93).

\section{References}

Bolman, L., \& Deal, T. (2013). Reframing organizations: Artistry, choice and leadership (5th ed.). San Francisco, CA: Jossey-Bass.

Downey, J. (2001). Guest editor's introduction: Academic leadership and organizational change. Innovative Higher Education, 25, 235-238. 